\title{
Mask Material Filtration Efficiency and Mask Fitting at the Crossroads: Implications during Pandemic
}

Aerosol and Air Quality Research

Special Issue:

Special Issue on COVID-19 Aerosol Drivers, Impacts and Mitigation (XV)

\section{Times}

\author{
Karin Ardon-Dryer ${ }^{1^{*}}$, Juliusz Warzywoda ${ }^{2}$, Rumeysa Tekin ${ }^{2}$, Jnev Biros ${ }^{3}$, \\ Sharilyn Almodovar ${ }^{4}$, Brandon L. Weeks ${ }^{5}$, Louisa J. Hope-Weeks ${ }^{6}$, \\ Albert Sacco Jr. ${ }^{3}$
}

\author{
${ }^{1}$ Department of Geosciences, Atmospheric Science Group, Texas Tech University, Lubbock, TX \\ 79409, USA \\ ${ }^{2}$ Materials Characterization Center, Edward E. Whitacre Jr. College of Engineering, Texas Tech \\ University, Lubbock, TX 79409, USA \\ ${ }^{3}$ Edward E. Whitacre Jr. College of Engineering, Texas Tech University, Lubbock, TX 79409, USA \\ ${ }^{4}$ Department of Immunology and Molecular Microbiology, Texas Tech University Health \\ Sciences Center, Lubbock, TX 79430, USA \\ ${ }^{5}$ Department of Chemical Engineering, Texas Tech University, Lubbock, TX 79409, USA \\ ${ }^{6}$ Department of Chemistry and Biochemistry, Texas Tech University, Lubbock, TX 79409, USA
}

\section{ABSTRACT}

The COVID-19 pandemic triggered the widespread use and need for respirators and face masks for the healthcare workers and public. In this study, several generally available respirators and mask designs were fit tested, and their materials were evaluated for filtration efficiency using $250 \mathrm{~nm}$ polystyrene latex particles. Efficiency testing was performed for 2 and $0.5 \mathrm{~h}$ at low $\left(2.6 \mathrm{~L} \mathrm{~min}^{-1}\right)$ and high $\left(7.4 \mathrm{~L} \mathrm{~min}^{-1}\right)$ airflows, respectively, using $\sim 17.4 \mathrm{~cm}^{2}$ material area. As expected, all N95 and KN95 respirators passed the fit test, and their materials showed efficiencies $>95 \%$ for the entire experiment at both airflows. Of the three air filters used in the 3D-printed Montana masks, only the HEPA filter had a filtration efficiency $>95 \%$ at both airflows. Regardless of the insert material, the Montana mask failed all fit tests. Homemade duckbill masks made of Halyard $\mathrm{H} 600$ sterilization wrap and WypAll X80 reusable wipe also failed the fit test, and both filter materials had an average filtration efficiency $<95 \%$ at high airflows. To explain the filtration efficiency results, the structure and composition of all filter materials were determined using FE-SEM, and IR and Raman spectroscopy. In conclusion, when highly efficient materials are used in masks that do not fit the users properly, the potential of these materials to protect the users from aerosols is compromised. Therefore, the mask design is as important as the filtration efficiency of the mask material.

Keywords: Respirators, Face masks, Duckbill masks, Filtration efficiency

\section{INTRODUCTION}

The Severe Acute Respiratory Syndrome Coronavirus 2 (SARS-CoV-2) caused the pandemic known as Coronavirus Disease 2019 (COVID-19), infecting $>97$ million people around the globe with $>2$ million deaths worldwide as of January 20, 2021 (Worldometer, 2020). COVID-19 spreads in the air as respiratory droplets and aerosols that are produced when an infected person coughs, sneezes, or talks (CDC, 2020a; Liu et al., 2020; Lu et al., 2020; Morawska and Cao, 2020; van Doremalen et al., 2020). The aerosol transmission via speaking involves generation of a large number of small $(<2 \mu \mathrm{m})$ droplets per second (Morawska et al., 2009; Asadi et al., 2019). These aerosols play an important role in spreading the infection (Morawska and Cao, 2020; Stadnytskyi 
et al., 2020; Wang and Du, 2020).

Wearing a mask significantly reduces and prevents transmission of human coronaviruses from both symptomatic and asymptomatic individuals (Leung et al., 2020). The most penetrating particle size (MPPS) of most mechanical filters used as masks is between 0.1 and $0.3 \mu \mathrm{m}$, while filters with electrostatic charge (e.g., N95) have smaller MPPS, typically below $0.8 \mu \mathrm{m}$ (Ou et al., 2020). Among the wide variety of face coverings available, N95 Filtering Facepiece Respirator (FFR) blocks $\geq 95 \%$ of solid or liquid particles with size of $0.3 \mu \mathrm{m}$, at an airflow of $85 \mathrm{~L} \mathrm{~min}^{-1}$ (NIOSH, 1997). Based on their performance standards, China KN95 FFRs (KN95 respirators) are considered to be equivalents to US N95 FFRs (3M Technical Bulletin, 2020). However, neither N95s or KN95s are recommended for public use as they are currently in short supply and require personal fit tests to prove effective; and therefore, should be used only by healthcare workers who are tested for fit periodically (CDC, 2020b).

The filtration efficiency of a mask, which represents the capture efficiency of mask material, is based on the particle concentration (particles $\mathrm{cm}^{-3}$ ) upstream and downstream (i.e., before and after particles pass through the filter/mask):

Effciency $(\%)=\left[1-\frac{\text { Downstream concentration }}{\text { Upstream concentration }}\right] \times 100$

There are several ways to evaluate a mask's performance and material filtration efficiency. Whereas some studies use a manikin headform with the full mask (Balazy et al., 2006a, b; He et al., 2013; Bahloul et al., 2014; Shakya et al., 2016; Adhikari et al., 2018; Kumar et al., 2020), other studies cut a portion of the mask/fabric and place it in a filter holder (Eshbaugh et al., 2008; Lin et al., 2017; Konda et al., 2020; Pei et al., 2020; Wang et al., 2020). Many studies use salt, e.g., $\mathrm{NaCl}$ (Eshbaugh et al., 2008; He et al., 2014; Lin et al., 2017; Pei et al., 2020), or polystyrene latex (PSL) spherical particles of defined sizes (Qian et al., 1997; Lee et al., 2005; Eshbaugh et al., 2008) to simulate particulate contaminants. The particle concentration used in these experiments varies from hundreds to several tens of thousands of particles per $\mathrm{cm}^{3}$ (Balazy et al., 2006a, b; Eshbaugh et al., 2008; He et al., 2014; Adhikari et al., 2018). A variety of flow rates were used in these tests (Eshbaugh et al., 2008; He et al., 2013; Bahloul et al., 2014; Adhikari et al., 2018), yet the most common flow rate is $85 \mathrm{~L} \mathrm{~min}^{-1}$, which represents breathing under heavy workload, similar to the condition defined by NIOSH (NIOSH, 2020). Lower flow rates are also commonly studied such as 15 and $30 \mathrm{~L} \mathrm{~min}^{-1}$ that represent breathing under light workload (Lee et al., 2005; Balazy et al., 2006a, b; He et al., 2013, 2014).

With the recommended use of masks in public, people began widely using homemade cloth face masks, including the duckbill style mask. A myriad of mask designs became available with various materials. For example, several 3D-printed mask models have been designed, such as the Stopgap Surgical Face Mask (NIH, 2020) or the Montana mask (The Montana mask, 2020a). In the meantime, medical grade fabric such as the Halyard $\mathrm{H} 600$ sterilization wrap (Halyard H600 Sterilization Wrap, 2020) started to be sewn into masks, especially for the healthcare workers who were looking for alternatives as respirators were in short supply. This material, typically used to wrap surgical instrument trays in hospitals during equipment sterilization (Halyard Worldwide, 2020), was recommended for efficiently blocking aerosols and droplets (UFHealth, 2020). "Blue shop towels", including the WypAll brand also received considerable attention as a homemade mask material. It was claimed that two layers of blue shop towels inserted in a tight-fitting cotton mask would block $82-93 \%$ of particles as small as $0.3 \mu \mathrm{m}$ (Business Insider, 2020; WypAll X80 Brand, 2020).

The current study aimed to examine the filtration efficiency of materials used in some N95 and KN95 respirators, and masks with the Montana, and duckbill designs. We also quantified the fit of these respirators/masks to the wearer's face. The filtration efficiency was measured under controlled laboratory conditions using $250 \mathrm{~nm}$ spherical PSL particles. The filtration efficiency was investigated over 2 and $0.5 \mathrm{~h}$ at the low and high flow rates, respectively since many of these respirators/masks are used for prolonged durations. Finally, to explain the filtration performance of these materials we determined the physical structure and composition of all filter materials. 


\section{METHODS}

\subsection{Materials}

Table 1 presents the commercially available respirators and masks materials investigated in this study. An HDX N95 respirator, certified by NIOSH (CDC, 2020c) was tested as reference. Two of KN95s tested (AOXING and ARUN) were recently evaluated by NIOSH (CDC, 2020d), but the NANO KN95 (NANO; 4C Air, 2020) has not been evaluated yet. Three different air filters were tested while inserted in a 3D-printed Montana mask (The Montana mask, 2020a). Duckbill masks were made from the Halyard $\mathrm{H} 600$ sterilization wrap or the WypAll X80 reusable wipe. Additional information on the investigated masks and materials can be found in the supplemental section.

\subsection{Materials Filtration Efficiency Testing}

A schematic of the experimental setup is shown in Fig. 1. An Atomizer - Aerosol Generation System (AGS - Model 9200, Brechtal, CA, USA) was used to generate spherical PSL particles with $250 \mathrm{~nm}$ diameter (Polysciences Inc. Nanobead NIST Traceable Particle Size Standard, $250 \mathrm{~nm}$ ). Both uncharged and charged PSL particles were generated by the atomizer. Charged PSL particles have a median charge between 10-100 elementary electron units (Whitby and Liu, 1968). Before passing a Brechtal $Y$ shape flow splitter, the condensed-phase water was removed from the aerosol by two in-line dryers that contain silica gel and are part of the atomizer system. The PSL particles were split into two flows, one flow going directly to Particle Counter $A$, the other flow first passing through a $47 \mathrm{~mm}$ Millipore aerosol filter holder before reaching Particle Counter B. Particle Counter B was connected to the external pump with a flow meter. The particle counters $A$ and $B$ were identical units of Portable Aerosol Spectrometer (PAS) GRIMM 11-D system (GRIMM Aerosol Technik GmbH \& Co. KG). These systems measure particle total concentration and size distribution in the size range of $0.25-35 \mu \mathrm{m}$. Measurements were averaged and recorded

Table 1. Respirators, masks and filter materials used.

\begin{tabular}{|c|c|c|c|c|c|}
\hline & $\begin{array}{l}\text { Mask Name / } \\
\text { Filter Name }\end{array}$ & Type of Mask / Type of Filter & Manufacturer or Vendor & $\begin{array}{l}\text { Electrostatically } \\
\text { charged based } \\
\text { on Manufacturer }\end{array}$ & $\begin{array}{l}\text { Number of } \\
\text { Sheets of Filter } \\
\text { Material in Mask }\end{array}$ \\
\hline \multirow[t]{4}{*}{ Respirator } & HDX N95 & Respirator / HDX H950 & Home Depot & Yes & As Is \\
\hline & AOXING KN95 & Respirator / AX-KF95 & $\begin{array}{l}\text { Dongguan AOXING AV } \\
\text { Equipment Co., Ltd. }\end{array}$ & Yes & As Is \\
\hline & NANO KN95 & Respirator / 4C Air Nano & $\begin{array}{l}\text { Chongqing Zhongnuo } \\
\text { Hengkang Biotechnology } \\
\text { Co., Ltd. Production }\end{array}$ & Yes & As Is \\
\hline & ARUN KN95 & Respirator / N9 & $\begin{array}{l}\text { Dongguan Arun Industrial } \\
\text { Co., Ltd. }\end{array}$ & Yes & As Is \\
\hline \multirow[t]{3}{*}{$\begin{array}{l}\text { Filter in } \\
\text { Montana } \\
\text { Mask }\end{array}$} & MERV 13-AIRx & $\begin{array}{l}\text { 3D-printed Montana Mask / } \\
\text { AIRx Health MERV } 13 \\
\text { Pleated Air Filter }\end{array}$ & AirX Filters & No & One \\
\hline & MERV 13-H & $\begin{array}{l}\text { 3D-printed Montana Mask / } \\
\text { Honeywell Elite Allergen } \\
\text { MERV } 13 \text { Pleated Air } \\
\text { Filter }\end{array}$ & Honeywell & No & One \\
\hline & HEPA & $\begin{array}{l}\text { 3D-printed Montana Mask / } \\
\text { Honeywell Filter R True } \\
\text { HEPA Replacement Filter }\end{array}$ & Honeywell & No & Two \\
\hline \multirow[t]{2}{*}{$\begin{array}{l}\text { Fabric in } \\
\text { Duckbill } \\
\text { Mask }\end{array}$} & WypAll X80 & $\begin{array}{l}\text { Homemade Duckbill Mask / } \\
\text { WypAll X80 Reusable } \\
\text { Wipe }\end{array}$ & Kimberly-Clark Professional & No & Two \\
\hline & Halyard H600 & $\begin{array}{l}\text { Homemade Duckbill Mask / } \\
\text { Halyard H600 } \\
\text { Sterilization Wrap (blue) }\end{array}$ & O\&M Halyard, Inc. & Yes & Two \\
\hline
\end{tabular}




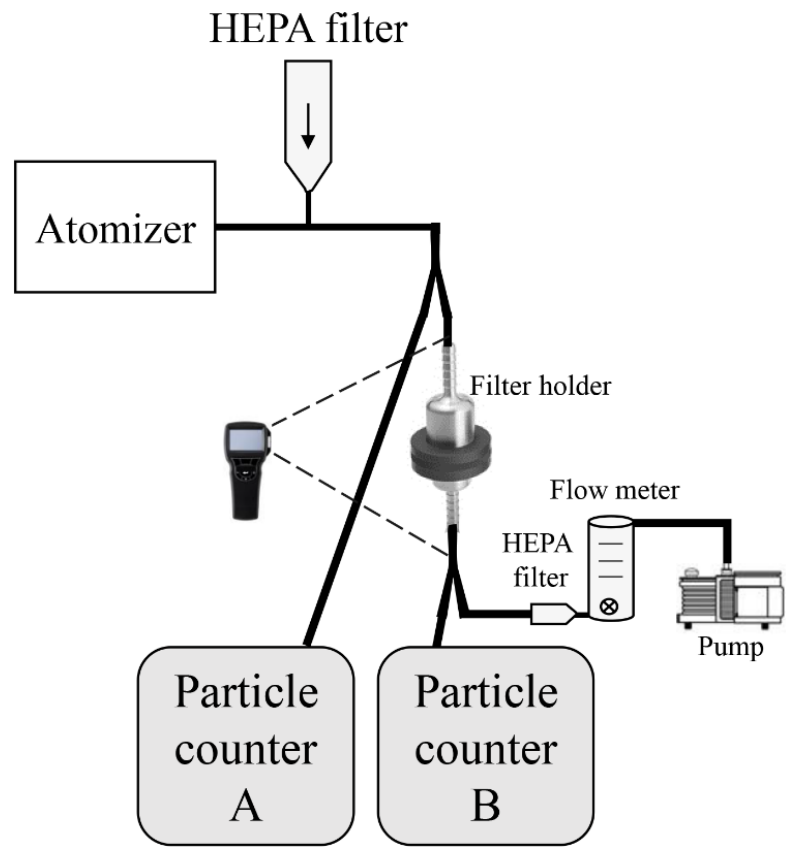

Fig. 1. Experimental setup.

every $1 \mathrm{~min}$. Flow rate was tested at the beginning and end of each experiment using mass flow meter (TSI-4043). Flow was also monitored by the flow meter (MATHESON, High Accuracy Flowmeter, FM-1050) that was connected to the external pump to detect any changes or fluctuations in flow rate. Pressure was measured before and after the filter holder using a TSI digital manometer (model \#AXD620). The pressure drop $(\Delta \mathrm{P})$ across the tested material was determined as an indicator of the material's comfort and breathability (Lord, 1959). Pressure drop across the sample was recorded every $10 \mathrm{~min}$. The total particle concentration used throughout the experiments (based on Particle Counter A measurements) was $278 \pm 76$ particles $\mathrm{cm}^{-3}$. Particle concentrations measured by the two particle counters, when connected directly to the atomizer, or when an empty filter holder was added to the system, were identical within the measurement error (260 \pm 39.5 particles $\mathrm{cm}^{-3}$ in Particle Counter A, and $254 \pm 37.3$ particles $\mathrm{cm}^{-3}$ in Particle Counter B). $93.6 \pm 4.0 \%$ of the PSL particles measured by Particle Counter A were in a size range of $0.25-$ $0.298 \mu \mathrm{m}$ whereas $5.5 \pm 3.4 \%$ of the particles were in a size range of $0.298-0.352 \mu \mathrm{m}$. Only less than $\sim 1 \%$ of particles measured were larger than $0.352 \mu \mathrm{m}$. The largest particles detected were $\sim 5 \mu \mathrm{m}$ in size. Some of these larger particles most likely formed when multiple PSL particles agglomerated in the wet-generation system during the generation process.

The filtration efficiency of each material was measured using a circular sample (diameter $47 \mathrm{~mm}$, surface area $\sim 17.4 \mathrm{~cm}^{2}$ ) cut from the respirator/mask (see an example in Fig. S1). This sample was placed in the $47 \mathrm{~mm}$ Millipore aerosol filter holder. Efficiency of each material was independently tested twice, each time with a new sample. The filtration efficiency was determined using the same number, sequence, and orientation of sheets as those used in fit testing.

Two flow rates were selected: a low flow rate of $2.6 \mathrm{~L} \mathrm{~min}^{-1}$, which is equivalent to flow velocity of $2.5 \mathrm{~cm} \mathrm{~s}^{-1}$; and a high flow rate of $7.4 \mathrm{~L} \mathrm{~min}^{-1}$, which is equivalent to flow velocity of $7.1 \mathrm{~cm} \mathrm{~s}^{-1}$. These two flow rates are equivalent to respiration at rest $\left(\sim 30 \mathrm{~L} \mathrm{~min}{ }^{-1}\right)$ and during exertion $(\sim 85$ $\mathrm{L} \mathrm{min}^{-1}$ ) (Lee et al., 2005; Bałazy et al., 2006a; He et al., 2014; Pei et al., 2020), considering the average surface area of an $\mathrm{N} 95\left(\sim 200 \mathrm{~cm}^{2}\right)$ (Roberge et al., 2010) and the surface area of our test materials. In order to provide a fair comparison of the ability of each material to capture $250 \mathrm{~nm}$ PSL particles, all materials were tested at the same flow rate. Since the filter material efficiency depends on the velocity of the flow passing through the filter (TSI Application Note ITI-041, 2020), our data provide a fair comparison of the filtration efficiency of each material with the same surface area, at the same flow velocity. However, respirators and masks investigated here had different surface areas $\left(\sim 40, \sim 180\right.$, and $\sim 270 \mathrm{~cm}^{2}$ for the Montana masks, respirators, and duckbill masks, respectively). Hence, the Montana mask would have a higher velocity of air flowing 
through its insert materials ( 12.5 and $35.4 \mathrm{~cm} \mathrm{~s}^{-1}$ under light and heavy workloads, respectively); whereas the respirators would have about the same $\left(2.8\right.$ and $\left.7.9 \mathrm{~cm} \mathrm{~s}^{-1}\right)$; and the duckbill mask would have smaller ( 1.9 and $5.2 \mathrm{~cm} \mathrm{~s}^{-1}$ ) compared to our experimental flow velocities ( 2.5 and $7.1 \mathrm{~cm} \mathrm{~s}^{-1}$ ). Since filter material efficiency and flow velocity are inversely proportional (Bałazy et al., 2006a; He et al., 2013), the Montana masks would have a smaller filtration efficiency (i.e., less efficient filtration); respirators would have similar (i.e., nearly the same filtration), and the duckbill masks would have larger filtration efficiency (i.e., more efficient filtration) compared to the results determined in our experiments.

\subsection{Filtration Efficiency Calculation}

The filtration efficiency was calculated every 1 min using Eq. (1), and then averaged for the entire test time. Efficiency was also calculated based on particle size using particle counter size bins.

\subsection{Mask Fit Testing}

Mask fit tests were performed using a TSI Portacount 8030 unit. The Portacount is a quantitative analyzer which measures the concentration inside the mask, in the breathing zone, and outside of the mask. The ratio of the number of particles inside the mask to the outside of the mask gives a "fit factor" where higher values indicate a better fit. To supplement the number of particles in the environment, a TSI NaCl particle generator 8026 was used during all fit test experiments. Both the real time and OSHA fit tests were conducted on each mask.

\subsection{Materials Characterization}

The field emission scanning electron microscope (FE-SEM) images were acquired on a Hitachi S-4700 FE-SEM (accelerating voltage $2 \mathrm{kV}$, beam current $10 \mu \mathrm{A}$, working distance $12 \mathrm{~mm}$ ) in the secondary electron imaging mode. The fiber diameters were measured using Image Processing and Analysis in Java (ImageJ, NIH). The Raman spectra of individual fibers were recorded on a Bruker Optics Senterra dispersive Raman microscope spectrometer with a spectral resolution of $\sim 3-5 \mathrm{~cm}^{-1}$, using $50 x$ microscope objective and $785 \mathrm{~nm}$ laser excitation. The infrared (IR) spectra of the outer layer $(\sim 2 \mu \mathrm{m})$ of fibrous samples were recorded on a Bruker Optics Vertex 70 Fourier transform infrared (FTIR) spectrometer (64 scans, resolution of $4 \mathrm{~cm}^{-1}$ ) with a Bruker Optics Platinum attenuated total reflection (ATR) accessory (diamond ATR crystal). Known materials made of polypropylene, polyester, polyethylene, polyethylene terephthalate, and cellulose were used as "standards" to identify the composition of the filter materials. The thickness of each mask was measured in multiple locations using a digital caliper.

\section{RESULTS AND DISCUSSION}

\subsection{Filtration Efficiency of Different Respirator/Mask Materials}

The average filtration efficiency of each respirator/mask material obtained from two independent tests is presented in Table 2. The $\mathrm{N} 95$ material had an average filtration efficiency $>95 \%$ at both flow rates, as expected. All three KN95 materials also had average filtration efficiencies $>95 \%$ at both flow rates. NIOSH examined two of the KN95 (ARUN and AOXING) at a flow rate of $85 \mathrm{~L} \mathrm{~min}^{-1}$, and found filtration efficiencies of 96.9-99.1\% for ARUN KN95 and 99.099.6\% for AOXING KN95, (CDC, 2020d). Our average filtration efficiency results of the ARUN KN95 material at high flow rate $(97.4 \pm 0.4 \%)$ match the NIOSH results. At high flow rate, AOXING KN95 had lower average filtration efficiency $(96.8 \pm 0.7 \%)$ than that measured by NIOSH (CDC, 2020d); however, it is still greater than the threshold level (95\%) required for KN95 (3M Technical Bulletin, 2020). All N95 and KN95 examined in this study passed fit testing (Table 3).

Although Montana design has been shown to pass fit tests (The Montana mask, 2020b), the Montana masks used in this work did not pass the fit test and failed each of the test parameters (Table 3). Thus, our data suggest these masks fit poorly to our subject's face and given the printed material is rather rigid, these masks can only fit a limited percentage of the population with a specific face shape. In order to confirm that the efficiency of the insert materials did not contribute 
Table 2. The average filtration efficiency of all respirator/mask materials (average \pm standard deviation) and the average pressure drop $(\Delta \mathrm{P})$ across the material (average \pm standard deviation) for the entire duration of the experiments, i.e., 2 and $0.5 \mathrm{~h}$ at the low and high flow rates, respectively.

\begin{tabular}{llllll}
\hline $\begin{array}{l}\text { Mask / Filter } \\
\text { Material Name }\end{array}$ & $\begin{array}{l}\text { Average Filtration } \\
\text { Efficiency at } \\
\text { Low Flow Rate (\%) }\end{array}$ & $\begin{array}{l}\text { Average Filtration } \\
\text { Efficiency at High } \\
\text { Flow Rate (\%) }\end{array}$ & $\begin{array}{l}\text { Average } \Delta \mathrm{P} \text { at } \\
\text { Low Flow Rate } \\
(\mathrm{Pa})\end{array}$ & $\begin{array}{l}\text { Average } \Delta \mathrm{P} \text { at High } \\
\text { Flow Rate } \\
(\mathrm{Pa})\end{array}$ & $\begin{array}{l}\text { Mask / Filter } \\
\text { Thickness } \\
(\mathrm{mm})\end{array}$ \\
\hline HDX N95 & $100.0 \pm 0.0$ & $99.7 \pm 0.0$ & $63 \pm 1$ & $199 \pm 1$ & $0.4 \pm 0.02$ \\
AOXING KN95 & $99.4 \pm 0.2$ & $96.8 \pm 0.7$ & $111 \pm 1$ & $338 \pm 0$ & $0.4 \pm 0.04$ \\
NANO KN95 & $100.0 \pm 0.0$ & $99.7 \pm 0.2$ & $36 \pm 0$ & $77 \pm 0$ & $0.3 \pm 0.02$ \\
ARUN KN95 & $99.7 \pm 0.1$ & $97.4 \pm 0.4$ & $77 \pm 1$ & $204 \pm 0$ & $0.3 \pm 0.02$ \\
MERV 13-AIRx & $84.7 \pm 6.0$ & $64.4 \pm 4.6$ & $7 \pm 0$ & $0 \pm 0$ & $0.1 \pm 0.02$ \\
MERV 13-H & $95.8 \pm 0.9$ & $85.8 \pm 1.3$ & $7 \pm 0$ & $12 \pm 0$ & $0.2 \pm 0.01$ \\
HEPA & $99.1 \pm 0.9$ & $99.0 \pm 0.1$ & $76 \pm 1$ & $166 \pm 0$ & $0.4 \pm 0.01$ \\
WypAll X80 & $52.9 \pm 4.1$ & $37.8 \pm 4.7$ & $35 \pm 0$ & $96 \pm 0$ & $0.4 \pm 0.02$ \\
Halyard H600 & $96.5 \pm 0.9$ & $89.1 \pm 1.4$ & $126 \pm 0$ & $342 \pm 1$ & $0.2 \pm 0.03$ \\
\hline
\end{tabular}

to the poor fit test results, we also evaluated the average efficiency of these materials (Table 2). Both the MERV 13-H and HEPA filters had average filtration efficiency $>95 \%$ at low flow rate. The HEPA filter performed $>95 \%$ at high flow rate, but MERV $13-\mathrm{H}$ efficiency decreased to $\sim 85 \%$ at this flow rate. The MERV 13-AIRx was the least efficient with average filtration efficiency $\sim 85 \%$ and $\sim 65 \%$ at the low and high flow rate, respectively. According to its manufacturer (AIRx Health MERV 13 Pleated Air Filter, 2020), the MERV 13-AIRx filter traps $90 \%$ of particles in the $1-3 \mu \mathrm{m}$ size range, including bacteria and viruses, which can be $<0.5 \mu \mathrm{m}$ in size. The particles used in this work are smaller than the size guaranteed by the manufacturer, hence our lower filtration efficiency results $(<90 \%)$. Although none of the Montana masks passed the fit test (Table 3 ), some of the filter materials (especially the HEPA filter) used in these masks were $>95 \%$ efficient in blocking the passage of particles. This eliminates the filtration efficiency of the filters as a contributing factor to low fit test results in Montana masks and confirms our hypothesis. Our investigation suggests 3D printed masks are typically not flexible enough to allow fit to a wide range of face shapes. While the mask material may be efficient, the mask itself might not protect its user.

Neither of the duckbill masks made of WypAll X80 or Halyard H600 passed the fit test (Table 3); however, we suspected the poor fit test results were attributable to the design of the masks itself. To test this hypothesis, we determined the average filtration efficiency of both materials at two flow rates (Table 2). At low flow rate, the WypAll X80 average filtration efficiency was $\sim 53 \%$, and it decreased to $\sim 38 \%$ at the high flow rate. The latter value is consistent with the Michigan mask response (2020) report, which found filtration efficiency of $30.6 \%$ at a flow rate of $60.8 \mathrm{~L} \mathrm{~min} \mathrm{mi}^{-1}$. The Halyard $\mathrm{H} 600$ average filtration efficiency was $>95 \%$, and $\sim 89 \%$ at low and high flow rate, respectively. The material tested in this work was a new (unused) Halyard $\mathrm{H} 600$ sterilization wrap but many masks used by the healthcare workers are made from used Halyard $\mathrm{H} 600$ wrap. We hypothesized that efficiencies of the new and used Halyard $\mathrm{H} 600$ wraps might be different. We tested this hypothesis by experimenting samples with two sheets of used Halyard $\mathrm{H} 600$ at a high flow rate. The average filtration efficiency of the used Halyard was lower $(82.6 \pm$ $1.7 \%)$ than that of the new Halyard (89.1 \pm 1.4 , Table 2$)$, as expected. Pei et al. (2020) examined the efficiency of one layer (sheet) of Halyard $\mathrm{H} 600$ and found efficiency of $\sim 65 \%$.

Regardless of the respirator/mask material tested, filtration efficiencies were lower at higher flow rate compared to lower flow rate (Table 2). Likewise, many studies reported decrease in efficiency at higher flow rates (Bałazy et al., 2006a; He et al., 2013). In most cases, the difference between the efficiencies at low and the high flow rate was small (a few percent at most). For the MERV 13-AIRx and MERV 13-H filters, and the WypAll X80 this difference was much larger ( 1020\%).

The average pressure drop $(\Delta \mathrm{P})$, a measure of material breathability, across all respirator/mask materials at both flow rates are displayed in Table 2. All materials showed average pressure drops $<343 \mathrm{~Pa}$, which is the maximum allowable pressure drop for $\mathrm{N} 95$ or equivalent respirators during inhalation (3M Technical Bulletin, 2020; CDC, 2020e). This suggests acceptable breathability of 


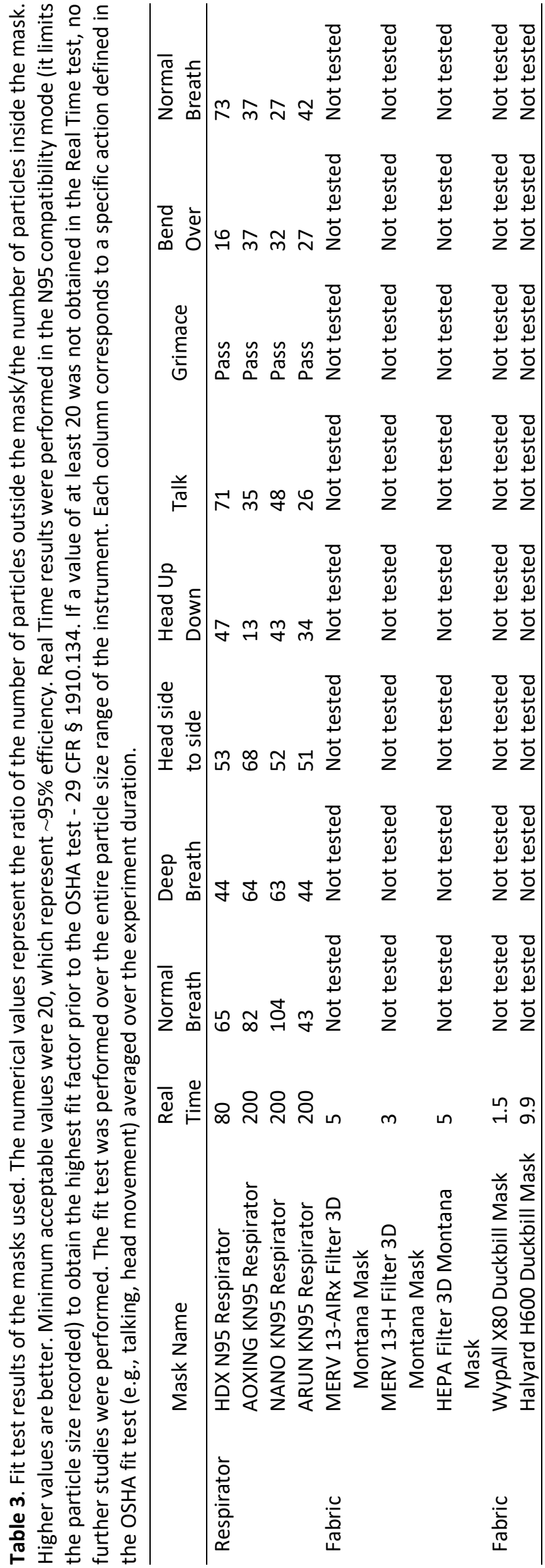



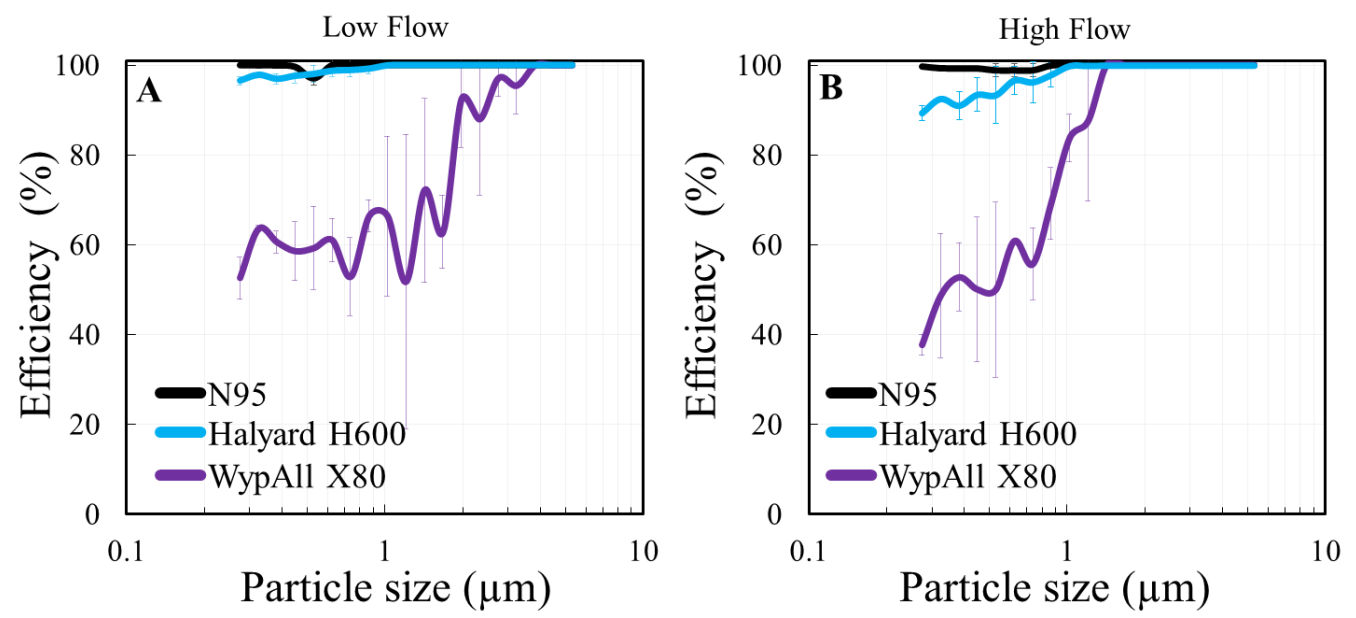

Fig. 2. Filtration efficiency versus particle size of the HDX N95 respirator material (black), the Halyard $\mathrm{H600}$ sterilization wrap (light blue), and the WypAll X80 reusable wipe (purple) at the low (A) and high (B) flow rates. Standard deviation lines represent values from two independent experiments.

the masks made from the materials tested using the similar number of sheets reported in this study. As expected, the average pressure drop across each material increased with an increased flow rate (3M Technical Bulletin, 2020). Mask thickness varied from 0.1 to $0.4 \mathrm{~mm}$ (Table 2). These values are in the thickness range used in Huang et al. (2013) theoretical model. Thicker masks had higher pressure drop as found by Shokri et al. (2015), but not necessarily higher filtration efficiency.

\subsection{Filtration Efficiency as a Function of Particle Size}

The variation in filtration efficiency as a function of particle size was investigated for some of the respirator/mask materials (Fig. 2). Both the low and high flow rate efficiencies were averaged based on the particle counter bin sizes. The filtration efficiency as a function of the particle size for the HDX N95 did not vary significantly, and was nearly identical, at both the low and high flow rates. However, the filtration efficiency of both the Wypall X80 and the Halyard $\mathrm{H} 600$ at both flow rates was lower for smaller particles and increased with larger particle size. This is consistent with the literature showing that the filtration efficiency of fibrous filters depends on the size of test particles (TSI Application Note ITI-041, 2020; Zangmeister et al., 2020). The filtration efficiency of the Halyard $\mathrm{H} 600$ was significantly larger than that of the Wypall X80 when particles with the same size were tested. Some of the variations of the efficiency versus particle size shown in Fig. 2 in the $1-5 \mu \mathrm{m}$ range is likely due to the low concentration of particles in this size range.

\subsection{Filtration Efficiency over Time}

Most studies do not provide information on the duration of the filtration efficiency tests. He et al. (2013) performed tests for $6 \mathrm{~min}$, while Lee et al. (2005) and Zangmeister et al. (2020) were $12 \mathrm{~min}$ and $15 \mathrm{~min}$, respectively. Both Mostofi et al. (2011) and Mahdavi (2013) performed long efficiency tests ( 5 and $6 \mathrm{~h}$, respectively) using manikin headform with $\mathrm{N} 95$ respirator and $\mathrm{NaCl}$ particles $(<200 \mathrm{~nm}$ ); however, only discrete hourly changes were reported without any values on the continuous change of the efficiency.

Change in the filtration efficiency over time is an important factor for the mask's performance. Since many mask users including healthcare workers may use masks for a prolonged time, the present study evaluated the temporal changes in the filtration efficiency of the tested mask materials. We were interested in determining whether the high efficiencies remain stable over a prolonged time. The filtration efficiency of each respirator/mask material was first evaluated for $2 \mathrm{~h}$ at low flow rate and then for $0.5 \mathrm{~h}$ at high flow rate. To the best of our knowledge, this is the first continuous filtration efficiency experiment for particles larger than $200 \mathrm{~nm}$. Temporal variations in filtration efficiency, reported every $5 \mathrm{~min}$, for both flow rates are shown in Fig. 3. 

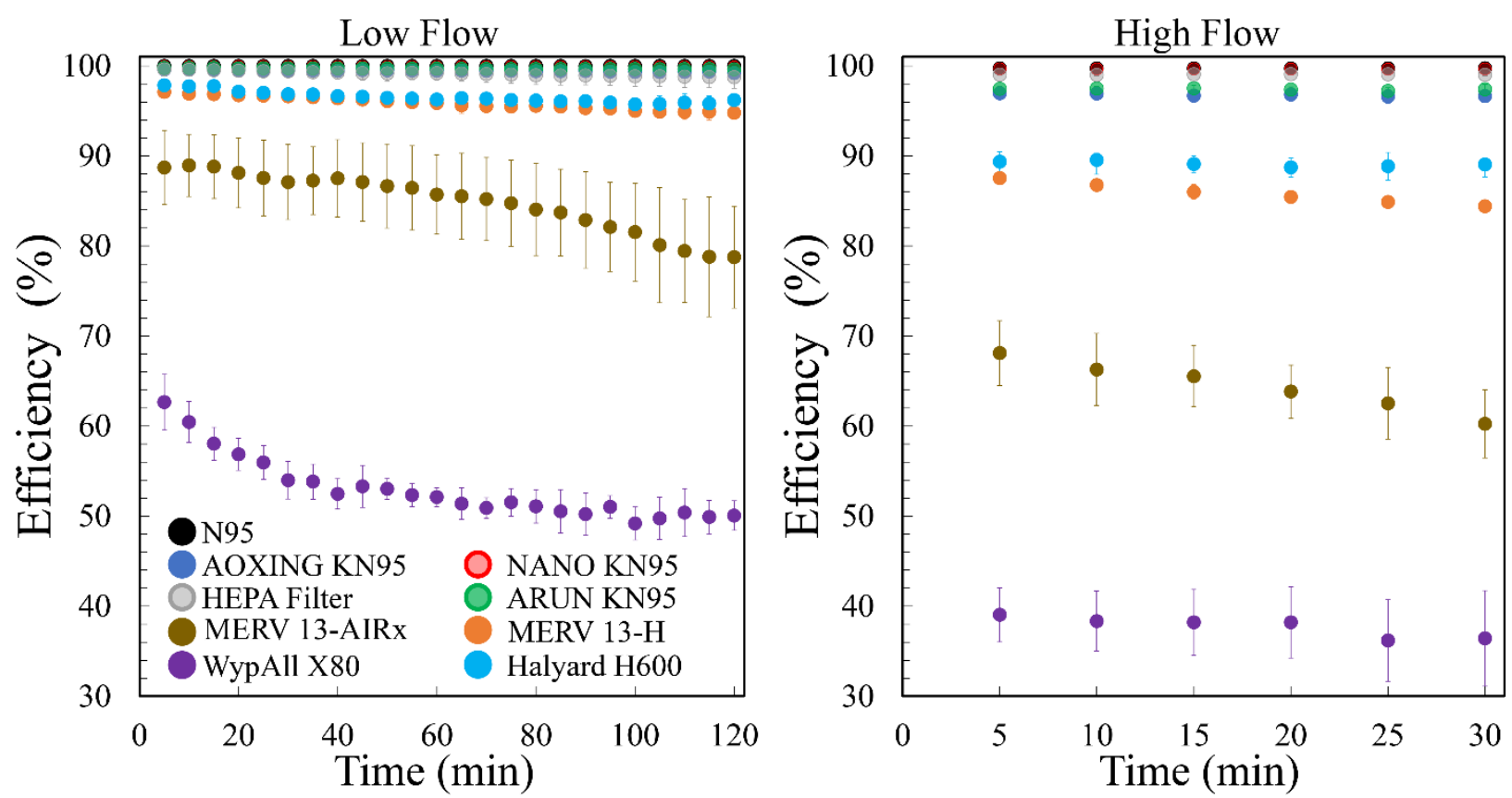

Fig. 3. Variation of the filtration efficiency over time for all respirator/mask materials for the entire duration of the experiments at two flow rates: low (left), and high (right). Every point represents 5 min average \pm range of values from two independent experiments.

The N95 and three KN95s exhibited stable efficiency throughout the experiment duration at both flow rates. Most respirators had stable and very high (>99\%) filtration efficiencies at both flow rates; however, at the high flow rate the ARUN KN95 and AOXING KN95 filtration efficiency was stable but slightly lower (>96.8\%). The filtration efficiency of the HEPA filter decreased only by $1.5 \%$ (from 99.6 to $98.1 \%$ ) at the low flow rate and was stable ( $99 \%$ ) at the high flow rate. The MERV 13-H filtration efficiency was quite stable and decreased by only $2.5 \%$ (from 97.1 to $94.6 \%$ ) and $3.2 \%$ (from 87.5 to $84.3 \%$ ) at the low and high flow rate, respectively. The efficiency of MERV 13-AIRx filter was lower and less stable over time; it decreased by $15.3 \%$ (from 88.9 to $73.6 \%$ ) and $7.9 \%$ (from 68.1 to $60.2 \%$ ) at low and high flow rates, respectively. At low flow rate, the WypAll X80 filtration efficiency decreased by $8.7 \%$ (from 62.7 to $54.0 \%$ ) during the first $0.5 \mathrm{~h}$ and by $16.0 \%$ (from 62.7 to $46.7 \%$ ) after $2 \mathrm{~h}$. At the high flow rate, however, it was much lower but more stable over time with a decrease of only $2.8 \%$ (from 39.0 to $36.2 \%$ ) during the corresponding period. The Halyard $\mathrm{H} 600$ had smaller temporal change in filtration efficiency at both flow rates with a decrease of $2.2 \%$ (from 97.9 to $95.7 \%$ ) and $0.8 \%$ (from 89.5 to $88.7 \%$ ) at the low and high flow rates, respectively. During prolonged testing with continuous sampling, the pressure drop values of almost all tested materials increased (average of 1.3 and 0.8 Pa for low and high flow rates, respectively), as expected (Eryu et al., 2011).

\subsection{Mask Materials Characterization}

To explain the results of filtration efficiency and the average pressure drop across the materials, structure of respirators and masks (e.g., number of sheets, fiber diameters) was examined using FE-SEM. Chemical composition of mask layers was determined using IR and Raman spectroscopy. The results are summarized in Table 4 and presented in detail in the supplemental section (Figs. S2-S10).

Both N95 and KN95 respirators were composed of four distinctive layers of nonwoven materials. All layers of the NANO and ARUN KN95 respirators were made of polypropylene. AOXING KN95 had three layers made of polypropylene and one layer of polypropylene and polyethylene. HDX N95 had one layer made of polyester and one layer of polypropylene and polyester combination in addition to two layers made of polypropylene. All respirators had uniform fiber diameters in each layer. Despite a slight variation of fiber diameters among different respirators, all outer layer fiber diameters were larger $(\sim 15-30 \mu \mathrm{m})$ than the inner layer fiber diameters $(\sim 1-8 \mu \mathrm{m})$. 
Table 4. Structure and composition of masks and mask materials.

\begin{tabular}{|c|c|c|c|c|}
\hline $\begin{array}{l}\text { Mask Name / } \\
\text { Filter Material Name }\end{array}$ & $\begin{array}{l}\text { Number of Sheets of } \\
\text { Filter Material in Mask }\end{array}$ & \multicolumn{2}{|c|}{ Filter Material Structure ${ }^{\mathrm{a}}$ and Chemical Composition } & Fiber Diameter $(\mu \mathrm{m})$ \\
\hline \multirow[t]{4}{*}{ HDX N95 } & As Is & Layer \#1 & Polypropylene & $18-26$ \\
\hline & & Layer \#2 & Polyester & $19-28$ \\
\hline & & Layer \#3 & Polypropylene & $1-5$ \\
\hline & & Layer \#4 & Polypropylene and Polyester & $16-27$ \\
\hline \multirow[t]{4}{*}{ AOXING KN95 } & As Is & Layer \#1 & Polypropylene & $19-28$ \\
\hline & & Layer \#2 & Polyethylene and Polypropylene & $16-25$ \\
\hline & & Layer \#3 & Polypropylene & $1-5$ \\
\hline & & Layer \#4 & Polypropylene & $20-29$ \\
\hline \multirow[t]{4}{*}{ NANO KN95 } & As Is & Layer \#1 & Polypropylene & $18-26$ \\
\hline & & Layer \#2 & Polypropylene & $16-26$ \\
\hline & & Layer \#3 & Polypropylene & $1-8$ \\
\hline & & Layer \#4 & Polypropylene & $19-28$ \\
\hline \multirow[t]{4}{*}{ ARUN KN95 } & As Is & Layer \#1 & Polypropylene & $13-22$ \\
\hline & & Layer \#2 & Polypropylene & $1-7$ \\
\hline & & Layer \#3 & Polypropylene & $1-7$ \\
\hline & & Layer \#4 & Polypropylene & $15-24$ \\
\hline \multirow[t]{2}{*}{ MERV 13-AIRx } & One & \multicolumn{2}{|c|}{ Polypropylene and Polyethylene } & $13-24$ \\
\hline & & \multicolumn{2}{|c|}{ Net-like structure on the upstream filter (layer) side } & $0.04-0.5$ \\
\hline MERV 13-H & One & Polypropylene & & $12-18$ \\
\hline \multirow[t]{3}{*}{ HEPA } & Two & Top Layer & Polyethylene terephthalate & $10-28$ \\
\hline & & Middle Layer & Polypropylene & $1-5$ \\
\hline & & Bottom Layer & Polyethylene terephthalate & $10-28$ \\
\hline \multirow[t]{2}{*}{ WypAll X80 } & Two & Upstream Side & Soft Pulp & $9-44^{b}$ \\
\hline & & Downstream Side & Polypropylene & $11-18$ \\
\hline \multirow[t]{3}{*}{ Halyard H600 } & Two & Top Layer & Polypropylene & $17-23$ \\
\hline & & Middle Layer & Polypropylene & $2-4$ \\
\hline & & Bottom Layer & Polypropylene & $17-23$ \\
\hline
\end{tabular}

${ }^{a}$ In a multilayered filter material the first layer listed was the upstream layer in the efficiency test experiments.

${ }^{b}$ Soft pulp fibers are not circular and have a belt-like appearance (Fig. S9). Dimensions shown for soft pulp fibers are those of their cross-sections that were measured for fiber orientations observed in the FE-SEM images.

A sheet of MERV 13-AIRx filter was made of a polypropylene and polyethylene combination and had fibers with diameters in the 13-24 $\mu \mathrm{m}$ range. The upstream side of this filter had a netlike structure with diameters in the $40-500 \mathrm{~nm}$ range. A sheet of MERV $13-\mathrm{H}$ consisted of polypropylene fibers with diameters in the 12-18 $\mu \mathrm{m}$ range. A single sheet of HEPA filter was composed of three layers. The outer layers were identical in general appearance, composition (polyethylene terephthalate), and fiber diameters $(10-28 \mu \mathrm{m})$. The middle layer was made of polypropylene and had fibers with diameters of 1-5 $\mu \mathrm{m}$.

A sheet of WypAll X80 was composed of two layers of soft pulp and polypropylene (WypAll X80 Reusable Wipes, 2020). The soft pulp layer was composed of fibers with belt-like shape and non-uniform dimensions (9-44 $\mu \mathrm{m})$; the polypropylene layer had fibers with diameters of 11$18 \mu \mathrm{m}$. A sheet of Halyard $\mathrm{H} 600$ was composed of three layers (Halyard Powerguard Technology, 2020). The two outer layers were made of spunbond polypropylene, with fiber diameters of 17$23 \mu \mathrm{m}$, whereas the middle layer was made of meltblown polypropylene with much smaller fiber diameters $(2-4 \mu \mathrm{m})$.

\subsection{What will Make an Efficient Mask}

Many factors including the flow velocity and particle (size distribution, concentration, and charge) as well as mask material characteristics (chemical composition, fiber diameters, electrostatic charge, mask thickness, and packing density) can affect the filtration efficiency of a given material (see Huang et al., 2013; Tcharkhtchi et al., 2021 for more details). Here we provide explanation of 
some of these factors. Since we tested each material under stable and constant flow conditions and under the same flow velocity, with the same particle type, size, concentration, and charge, we conclude that our filtration efficiency results reflect the performance of the masks and the respirators. We characterized the tested mask materials to further discuss what could make a mask efficient. It has been suggested that masks comprised of polypropylene and polyester will be effective in filtering particles (Lustig et al., 2020; Zangmeister et al., 2020). Chemical characteristics of the respirators examined here supports this hypothesis; however, other factors including but not limited to packing density, thickness, orientation, and fibers diameters in the individual layers also appeared to play a role in the filtration efficiency. Thicker masks had higher filtration efficiencies, with the exception of WypAll X80 and Halyard H600, which suggests that factors other than thickness contributed to the filtration efficiency. The filter materials with relatively larger average pressure drop across the material contained at least one layer of densely distributed fibers in vastly random orientation with fine diameters in the 1-8 $\mu \mathrm{m}$ range. This layer in respirators and Halyard $\mathrm{H} 600$ is made from meltblown nonwoven polypropylene fabric, which is electrostatically charged (Halyard Powerguard Technology, 2020; Liao et al., 2020). The electrostatic charge improves the collection of particles (Pei et al., 2020), mainly of small sizes (Huang et al., 2013; Ardon-Dryer et al., 2015), and credited with improving the filtration efficiency of N95-grade respirators for particles in the most penetrating size range (Liao et al., 2020). The HEPA filter, inserted in the Montana mask, which is as thick as the N95 and KN95s, but has no electrostatic charge, was as efficient as these respirators in capturing $250 \mathrm{~nm}$ particles. The presence of a layer composed of densely and randomly distributed fibers with small diameters distinguishes the non-electret HEPA filter from the two other less efficient non-electret filters (MERV 13-AIRx and MERV 13-H) is likely responsible for the HEPA filter high efficiency (Huang et al., 2013). A vast difference between the filtration efficiency of WypAll X80 and Halyard $\mathrm{H} 600$ can be attributed to the different filtration mechanisms of these fabrics. Whereas both are made of polypropylene, Halyard $\mathrm{H} 600$ is thinner but has the advantage of electrostatic charge (Ou et al., 2020) as well as the finer and more densely packed fibers in the middle layer. All these features are characteristic of the efficient N95 and KN95s examined here. Therefore, it appears there is not just one factor but a combination of factors that contributes to a high mask filtration efficiency. Although the filtration efficiency of the mask material is important, poor mask fit may lead to leakage. Thus, mask fit is another important factor that should be considered (Tcharkhtchi et al., 2021). This work highlights the importance of both filtration efficiency and mask fit as two major determinants of mask performance. Poor fit of the mask to the user's face may render a highly efficient mask filter material ineffective, as demonstrated by three air filters used in the 3D-printed Montana masks. All three filters had an overall good filtration efficiency; but none of these masks passed the fit test and they failed in each of the test parameters. The Montana mask was rigid and probably will only fit a small population with a specific face shape. New designs with improved malleability should be developed. As an example, nose bridge strips or additional layer (Huang et al., 2013; Zangmeister et al., 2020) might improve the mask's ability to protect the users by leveraging the filtration efficiency of high performing materials like Halyard $\mathrm{H} 600$ while still meeting the requirements for air resistance.

\section{CONCLUSIONS}

The efficiency of several mask materials in filtering $250 \mathrm{~nm}$ PSL particles was evaluated. All examined respirators exhibited initial filtration efficiencies $>95 \%$ (characteristic of the N95 or equivalent respirators) that remained stable ( $>95 \%$ ) during prolonged test durations ( $2 \mathrm{~h}$ at low and $0.5 \mathrm{~h}$ at high flow rates). All respirators passed the fit test. Only one (HEPA) of three (MERV 13-AIRx, MERV 13-H, and HEPA) air filters as potential filters in the 3D-printed Montana masks had efficiency $>95 \%$ at the high flow rate; the other two filters were less efficient ( 65-86\%). At the low flow rate, the MERV 13-AIRx was the filter that performed poorly ( $85 \%)$. The Montana masks did not pass fit testing with any of these filters. The WypAll X80 and the Halyard H600 were tested for a potential use in the homemade duckbill masks. The Halyard $\mathrm{H} 600$ had efficiency of $\sim 97$ and $\sim 89 \%$ at low and high flow rates, respectively. The average filtration efficiency of WypAll X80 was much lower ( $\sim 53$ and $\sim 38 \%$ at the low and high flow rates, respectively). Duckbill masks made from both the Halyard $\mathrm{H} 600$ and WypAll X80 fabrics failed fit testing. 
Temporal variation of the filtration efficiency of all filter materials was evaluated. Most materials showed stable filtration efficiencies (maximum change $3.3 \%$ over time) except for two materials (MERV 13-AIRx and WypAll X80) whose efficiency decreased by $\sim 8-16 \%$. These results may guide the users in deciding which mask materials will be used for a prolonged time.

The structure and composition of all filter materials were determined using FE-SEM, IR, and Raman spectroscopy to examine the filtration performance. All high performing materials were found to be electrostatically charged (with the exception of the HEPA filter) with at least one layer comprised of densely and randomly distributed fibers with fine diameters in the 1-8 $\mu \mathrm{m}$ range. The high filtration efficiency of a material contributes to the mask's potential to effectively protect the user but the mask's ability to fit the user is undeniably as important. Hence, as shown in our study, when masks made of highly efficient materials do not fit the user, the potential of these materials for protecting the user is compromised. To leverage the filtration efficiency of high performing materials like Halyard $\mathrm{H600}$, new designs with better fit should be developed.

\section{ACKNOWLEDGMENTS}

We gratefully acknowledge the Dean's Council of the Edward E. Whitacre Jr. College of Engineering and other generous alumni supporting us in our help the people of West Texas.

\section{DISCLAIMER}

The authors declare that they have no conflicts of interest.

\section{SUPPLEMENTARY MATERIAL}

Supplementary data associated with this article can be found in the online version at https://doi.org/10.4209/aaqr.200571

\section{REFERENCES}

3M Technical Bulletin (2020). Comparison of FFP2, KN95, and N95 and Other Filtering Facepiece Respirator Classes. https://multimedia.3m.com/mws/media/17915000/comparison-ffp2-kn95n95-filtering-facepiece-respirator-classes-tb.pdf (accessed 1 August 2020).

4C Air (2020). Nano KN95 Respirator. Nanomaterial-based filters. https://www.4cair.com/ product.html (accessed 17 August 2020).

Adhikari, A., Mitra, A., Rashidi, A., Ekpo, I., Schwartz, J., Doehling, J. (2018). Field evaluation of N95 filtering facepiece respirators on construction jobsites for protection against airborne ultrafine particles. Int. J. Environ. Res. Public Health 15, 1958. https://doi.org/10.3390/ijerph1 5091958

AIRx Health MERV 13 Pleated Air Filter (2020). https://airxfilters.com/\#our-products (accessed 17 August 2020).

Ardon-Dryer, K., Huang, Y.W., Cziczo, D.J. (2015). Laboratory studies of collection efficiency of sub-micrometer aerosol particles by cloud droplets on a single-droplet basis. Atmos. Chem. Phys. 15, 9159-9171. https://doi.org/10.5194/acp-15-9159-2015

Arkles, B. (2006). Hydrophobicity, Hydrophilicity and Silanes. Paint \& Coatings Industry. pp. 114135.

Asadi, S., Wexler, A.S., Cappa, C.D., Barreda, S., Bouvier, N.M., Ristenpart, W.D. (2019). Aerosol emission and superemission during human speech increase with voice loudness. Sci. Rep. 9, 2348. https://doi.org/10.1038/s41598-019-38808-z

Bahloul, A., Mahdavi, A., Haghighat, F., Ostiguy, C. (2014). Evaluation of N95 filtering facepiece respirator efficiency with cyclic and constant flows. J. Occup. Environ. Hyg. 11, 499-508 https://doi.org/10.1080/15459624.2013.877590

Balazy, A., Toivola, M., Adhikari, A., Sivasubramani, S.K., Reponen, T., Grinshpun S. A. (2006b). Do N95 respirators provide $95 \%$ protection level against airborne viruses, and how adequate are 
surgical masks? Am. J. Infect. Control 34, 51-77. https://doi.org/10.1016//j.ajic.2005.08.018

Bałazy, A., Toivola, M., Reponen, T., Podgórski, A., Zimmer, A., Grinshpun, S.A. (2006a). Manikinbased performance evaluation of N95 filtering-facepiece respirators challenged with nanoparticles. Ann. Occup Hyg. 50, 259-269. https://doi.org/10.1093/annhyg/mei058

Business Insider (2020). Using blue shop towels in homemade face masks can filter particles $2 x$ to $3 x$ better than cotton, 3 clothing designers discover after testing dozens of fabrics. https://www.businessinsider.com/homemade-mask-using-hydro-knit-shop-towel-filtersbetter-2020-4 (accessed 17 August 2020).

Centers for Disease Control and Prevention (CDC) (2019). NIOSH Standard Respirator Testing Procedures, TEB-APR-STP-0059. https://www.cdc.gov/niosh/npptl/stps/pdfs/TEB-APR-STP0059-508.pdf (accessed 17 August 2020).

Centers for Disease Control and Prevention (CDC) (2020a). How COVID-19 Spreads. https://www.cdc.gov/coronavirus/2019-ncov/prevent-getting-sick/how-covid-spreads.html? CDC_AA_refVal=https\%3A\%2F\%2Fwww.cdc.gov\%2Fcoronavirus\%2F2019-ncov\%2Fprepare\% 2Ftransmission.html (accessed 10 Aug 2020).

Centers for Disease Control and Prevention (CDC) (2020b). Personal Protective Equipment: Questions and Answers. https://www.cdc.gov/coronavirus/2019-ncov/hcp/respirator-usefaq.html (accessed 17 August 2020).

Centers for Disease Control and Prevention (CDC) (2020c). NIOSH-Approved N95 Particulate Filtering Facepiece Respirators. https://www.cdc.gov/niosh/npptl/topics/respirators/disp_pa rt/n95list1-h.html (accessed 17 August 2020).

Centers for Disease Control and Prevention (CDC) (2020d). NPPTL Respirator Assessments to Support the COVID-19 Response. International Assessment Results - Not NIOSH-approved. https://www.cdc.gov/niosh/npptl/respirators/testing/NonNIOSHresults.html (accessed 19 August 2020).

Centers for Disease Control and Prevention (CDC) (2020e). National Institute for Occupational Safety and Health. Determination of Particulate Filter Efficiency Level for N95 Series Filters Against Solid Particulates for Non-Powdered, Air-Purifying Respirators Standard Testing Procedure (STP) (2019), TEB-APR-STP-0059. https://wwwn.cdc.gov/PPEInfo/Standards/Info/T EBAPRSTP0059 (accessed 19 August 2020).

Eryu, K., Seto, T., Furuuchi, M., Otani, Y., Tajima, N., Kato, T. (2011). Effects of filter packing density and particle deposit on classification performance of inertial filter for sampling of PMo.1. J. Chem. Eng. Jpn. 44, 609-615, https://doi.org/10.1252/jcej.11we101

Eshbaugh, J.P., Gardner, P.D., Richardson, A.W., Hofacre, K.C. (2008). N95 and P100 respirator filter efficiency under high constant and cyclic flow. J. Occup. Environ. Hyg. 6, 52-61. https://doi.org/10.1080/15459620802558196

Halyard H600 Sterilization Wrap (2020) https://mms.mckesson.com/product/810876/OMHalyard-Inc-34164 (accessed 17 August 2020).

Halyard Powerguard Technology (1999). https://www.halyardhealth.co.uk/media/17525807 /hc470-01-uk_powerguardtechnology_20152.pdf (accessed 17 August 2020).

Halyard Worldwide (2020) https://products.halyardhealth.com/surgical-solutions/sterilizationsolutions/sterilization-wraps/halyard-kimguard-one-step-sterilization-wrap.html (accessed 17 August 2020).

He, X., Reponen, T., McKay R.T., Grinshpun, S.A. (2013). Effect of particle size on the performance of an $\mathrm{N} 95$ filtering facepiece respirator and a surgical mask at various breathing conditions. Aerosol Sci. Technol. 47, 1180-1187. https://doi.org/10.1080/02786826.2013.829209

He, X., Reponen, T., McKay, R., Grinshpun, S.A. (2014). How does breathing frequency affect the performance of an $\mathrm{N} 95$ filtering facepiece respirator and a surgical mask against surrogates of viral particles? J. Occup. Environ. Hyg. 11, 178-185. https://doi.org/10.1080/15459624.2013.8 48037

Honeywell Elite Allergen MERV 13 Pleated Air Filter. https://www.aafintl.com/en/residential/br owse-products/residential/brand/honeywell/honeywell-elite-allergen (accessed 17 August 2020).

Honeywell Filter R True HEPA Replacement Filter. https://www.amazon.com/Honeywell-FilterTrue-HEPA-Replacement/dp/BOOBWYOOLI (accessed 17 August 2020).

Huang, S.H., Chen, C.W., Kuo, Y.M., Lai, C.Y., McKay, R., Chen, C.C. (2013). Factors affecting filter 
penetration and quality factor of particulate respirators, Aerosol Air Qual. Res. 13, 162-171. https://doi.org/10.4209/aaqr.2012.07.0179

Konda, A., Prakash, A., Moss, G. A., Schmoldt, M., Grant, G.D., Guha, S. (2020). Aerosol filtration efficiency of common fabrics used in respiratory cloth masks. ACS Nano 14, 6339-6347. https://doi.org/10.1021/acsnano.0c03252

Kumar, A., Sangeetha, D.N., Yuvaraj, R., Menaka, M., Subramanian, V., Venkatraman, B. (2020). Quantitative performance analysis of respiratory facemasks using atmospheric and laboratory generated aerosols following with gamma sterilization. Aerosol Air Qual. Res. 21, 200349. https://doi.org/10.4209/aaqr.2020.06.0349

Lee, B.U., Yermakov, M., Grinshpun, S.A. (2005). Filtering efficiency of N95- and R95-type facepiece respirators, dustmist facepiece respirators, and surgical masks operating in unipolarly ionized indoor air environments. Aerosol Air Qual. Res. 5, 25-38. https://doi.org/10.4209/aaq r.2005.06.0003

Leung, N.H.L., Chu, D.K.W., Shiu, E.Y.C., Chan, K.H., McDevitt, J.J., Hau, P.J.P., Yen, H.L., Li, Y., Ip, D.K.M., Peiris, J.S.M., Seto, W.H., Leung, G.M., Milton, D.K., Cowling, B.J. (2020). Respiratory virus shedding in exhaled breath and efficacy of face masks. Nat. Med. 26, 676-680. https://doi.org/10.1038/s41591-020-0843-2

Liao, L., Xiao, W., Zhao, M., Yu, X., Wang, H., Wang, Q., Chu, S., Cui Y. (2020). Can N95 respirators be reused after disinfection? How many times? ACS Nano 14, 6348-6356. https://doi.org/10.1 021/acsnano.0c03597

Lin, T.H., Chen, C.C., Huang, S.H., Kuo, C.W., Lai, C.Y., Lin, W.Y. (2017). Filter quality of electret masks in filtering $14.6 \pm 594 \mathrm{~nm}$ aerosol particles: Effects of five decontamination methods. PLoS ONE 12, e0186217. https://doi.org/10.1371/journal.pone.0186217

Liu, Y., Ning, Z., Chen, Y., Guo, M., Liu, Y., Gali, N. K., Sun, L., Duan, Y., Cai, J., Westerdahl, D., Liu, X., Xu, K., Ho, K. f., Kan, H., Fu, Q., Lan, K. (2020). Aerodynamic analysis of SARS-CoV-2 in two Wuhan hospitals. Nature 582, 557-560. https://doi.org/10.1038/s41586-020-2271-3

Lord, J. (1959). The determination of the air permeability of fabrics. J. Text. I. 50, 569-582. https://doi.org/10.1080/19447025908659937

Lu, J., Gu, J., Li, K., Xu, C., Su, W., Lai, Z., Zhou, D., Yu, C., Xu, B., Yang, Z. (2020). COVID-19 outbreak associated with air conditioning in restaurant, Guangzhou, China, 2020. Emerg. Infec. Dis. 26, 1628-1631. https://doi.org/10.3201/eid2607.200764

Lustig, R., Biswakarma, J.J.H., Rana, D., Tilford, S.H., Hu, W., Su, M., Rosenblatt, M.S. (2020) Effectiveness of common fabrics to block aqueous aerosols of virus-like nanoparticles steven. ACS Nano 14, 7651-7658. https://doi.org/10.1021/acsnano.0c03972

Mahdavi, A. (2013). Efficiency Measurement of N95 Filtering Facepiece Respirators against Ultrafine Particles under Cyclic and Constant Flows, Concordia University.

Michigan mask response (2020). How well do homemade mask materials compare against the N95 standard? https://www.maskfaq.com/test-results (accessed 17 August 2020).

Morawska, L., Cao, J. (2020). Airborne transmission of SARS-CoV-2: The world should face the reality. Environ. Int. 139, 105730. https://doi.org/10.1016/j.envint.2020.105730

Morawska, L., Johnson, G.R., Ristovski, Z.D., Hargreaves, M., Mengersen, K., Corbett, S., Chao, C.Y.H., Li, Y., Katoshevski, D. (2009). Size distribution and sites of origin of droplets expelled from the human respiratory tract during expiratory activities. J. Aerosol Sci. 40, 256-269, https://doi.org/10.1016/j.jaerosci.2008.11.002

Mostofi, R., Bahloul, A., Lara, J., Wang, B., Cloutier, Y., Haghighat, F. (2011). Investigating of potential affecting factors on performance of N95 respirator. JISRP 28, 26-39.

National Institute for Occupational Safety and Health (NIOSH) (1997). 42 CFR 84 Respiratory Protective Devices; Final Rules and Notice. U.S. Centers for Disease Control and Prevention, National Institute for Occupational Safety and Health; Washington, DC, USA: 1997. Federal Register 60:110

NIH, 3D print exchange (2020). Stopgap Surgical Face Mask (SFM). https://3dprint.nih.go v/discover/3dpx-013429 (accessed 17 August 2020).

Ou, Q., Pei, C., Chan Kim, S., Abell, E., Pui, D.Y.H. (2020). Evaluation of decontamination methods for commercial and alternative respirator and mask materials - view from filtration aspect. J. Aerosol Sci. 150, 105609. https://doi.org/10.1016/j.jaerosci.2020.105609

Pei, C., Ou, Q., Kim, S.C., Chen, S.C., Pui, D.Y.H. (2020). Alternative face masks made of common 
materials for general public: Fractional filtration efficiency and breathability perspective. Aerosol Air Qual. Res. 20, 2581-2591. https://doi.org/10.4209/aaqr.2020.07.0423

Qian, Y., Willeke, K., Ulevicius, V., Grinshpun S.A. (1997). Particle reentrainment from fibrous filters. Aerosol Sci. Technol. 27, 394-404. https://doi.org/10.1080/02786829708965480

Roberge R.J., Bayer E., Powell, J.B., Coca, A., Roberge, M.R., Benson, S.M. (2010). Effect of exhaled moisture on breathing resistance of $n 95$ filtering facepiece respirators. Ann. Occup. Hyg. 54, 671-677. https://doi.org/10.1093/annhyg/meq042

Shakya, K.M., Noyes, A., Kallin, R., Peltier, R.E. (2017). Evaluating the efficacy of cloth facemasks in reducing particulate matter exposure. J. Exposure Sci. Environ. Epidemiol. 27, 352-357. https://doi.org/10.1038/jes.2016.42

Shokri, A., Golbabaei, F., Seddigh-Zadeh, A., Baneshi, M.R., Asgarkashani, N., Faghihi-Zarandi, A. (2015). Evaluation of physical characteristics and particulate filtration efficiency of surgical masks used in Iran's hospitals, Int. J. Occup. Hyg. 7, 10-16.

Tcharkhtchi, A., Abbasnezhad, N., Zarbini Seydani, M., Zirak, N., Farzaneh, S., Shirinbayan, M. (2021). An overview of filtration efficiency through the masks: Mechanisms of the aerosols penetration. Bioact. Mater. 6, 106-122. https://doi.org/10.1016/j.bioactmat.2020.08.002

The Montana mask (2020a). Make the mask. https://www.makethemasks.com/about-the-mask (accessed 17 August 2020).

The Montana mask (2020b). Respiratory and fit tests, https://static1.squarespace.com/sta tic/5e79449be223500c15da852f/t/5e7e663f06b4c351220683de/1585342016322/Mask+Fit+ Test+Report+Comparison+.pdf (accessed 17 August 2020).

TSI Application Note ITI-041 (A4) (2020) Mechanisms of filtration for high efficiency fibrous filters. https://www.tsi.com/getmedia/4982cf03-ea99-4d0f-a660-42b24aedba14/ITI-041-A4 ?ext=.pdf (accessed 17 August 2020).

UFHealth Department of Anesthesiology (2020). Frequently Asked Questions. https://anest. ufl.edu/clinical-divisions/mask-alternative/frequently-asked-questions/ (accessed 17 August 2020).

van Doremalen, N., Bushmaker, T., Morris, D.H., Holbrook, M.G., Gamble, A., Williamson, B.N., Tamin, A., Harcourt, J.L., Thornburg, N.J., Gerber, S.I., Lloyd-Smith, J.O., de Wit, E., Munster, V.J. (2020). Aerosol and surface stability of SARS-CoV-2 as compared with SARS-CoV-1. N. EngI. J. Med. 382, 1564-1567. https://doi.org/10.1056/NEJMc2004973

Wang, J., Du, G. (2020). COVID-19 may transmit through aerosol. Ir. J. Med. Sci. 24, 1-2. https://doi.org/10.1007/s11845-020-02218-2

Wang, P., Liu, Z., Chen, D.R. (2020). Performance of composite filters assembled from multiple layers of basic filtration media. Aerosol Air Qual. Res. 20, 2299-2308. https://doi.org/10.4209/ aaqr.2020.07.0368

Whitby, K.T., Liu, B.Y.H. (1968) Polystyrene aerosols-electrical charge and residue size distribution. Atmos. Environ. 2, 103-116. https://doi.org/10.1016/0004-6981(68)90026-7

World Health Organization (WHO) (2020). Rational use of personal protective equipment (PPE) for coronavirus disease (COVID-19). https://www.who.int/publications/i/item/rational-useof-personal-protective-equipment-for-coronavirus-disease-(covid-19)-and-considerationsduring-severe-shortages (accessed 26 March 2020).

Worldometer (2020). COVID-19 coronavirus pandemic. https://www.worldometers.info/cor onavirus/\#countries (accessed 20 January 2021).

WypAll X80 Brand (2020). https://www.businessinsider.com/instructions-for-making-blue-shoptowel-surgical-masks-2020-4 (accessed 17 August 2020).

WypAll X80 Reusable Wipes (2020) https://www.amazon.com/WypAll-41041-Cloths-HYDRO KNIT-Wipers/dp/B0040ZOFSE (accessed 17 August 2020).

Zangmeister, C.D., Radney, J.G., Vicenzi, E.P., Weaver, J.L. (2020). Filtration efficiencies of nanoscale aerosol by cloth mask materials used to slow the spread of SARS CoV-2. ACS Nano 14, 9188-9200. https://doi.org/10.1021/acsnano.0c05025 